\title{
A Cultural Discourse Analysis to Chinese Martial Arts Movie in the Context of Glocalization: Taking Crouching Tiger, Hidden Dragon and Hero as Cases
}

\author{
Junchen Zhang*
}

Faculty of Humanities, The Hong Kong Polytechnic University, Hong Kong, P.R. China

Corresponding Author: Junchen Zhang, E-mail: junchen.zhang@connect.polyu.hk

\section{ARTICLE INFO}

Article history

Received: January 14, 2019

Accepted: April 23, 2019

Published: June 30, 2019

Volume: 10 Issue: 3

Advance access: May 2019

Conflicts of interest: None

Funding: None

\author{
Key words: \\ Cultural Discourse Analysis, \\ Chinese Film, \\ Glocalization, \\ Cultural Ideology, \\ Cultural Hybridization, \\ Discursive Construction, \\ Cultural Communication
}

\begin{abstract}
This study is oriented to do Chinese cultural discourse analysis via examining two Chinese Wu-Xia (martial arts) movies. Specifically, the study explores the construction of glocalization, cultural hybridization and cultural discourse embedded in the two transnational Chinese martial arts movies, i.e. Ang Lee's Crouching Tiger, Hidden Dragon (2000) and Zhang Yimou's Hero (2002). The film product is an audiovisual representation of a certain of national culture, ideology and society. Chinese martial arts film is this kind of cultural product that embodies Chinese sociocultural and philosophical values. The research aims to explore the connections between filmic discourse, culture and society. A combined analytical framework that integrates glocalization concept, cultural hybridization and cultural discourse approach is constructed. By comparative analysis, the main finding of the study reveals that Ang Lee's Crouching Tiger, Hidden Dragon (2000) presents a high degree of cultural globalization and hybridization, while Zhang Yimou's Hero (2002) has relatively a low degree of cultural globalization and hybridization but embodies a high degree of Chinese locally authoritarian culture. This implies that a successful filmic production with strong national features need to organically hybridize global-local culture in proper when it enters globally cultural competition. On the one hand, it should have locally cultural identity; on the other, it should also show a kind of universally cultural values accepted by other cultures.
\end{abstract}

\section{INTRODUCTION}

Globalization has permeated into different national cultures nowadays, meanwhile localization should not be neglected in that it plays an integral part in the globalization process (Klein, 2004). In the context of cultural globalization, transnational Chinese language films present a phenomenon of cultural hybridization. One of distinctive Chinese film genres presenting cultural hybridization in globalized context is Chinese $\mathrm{Wu}$-Xia (martial arts) film. The Chinese martial arts film is originally a very Chinese-style film genre and it has been widely accepted in Chinese culture communities around the world over the past decades, such as Hong Kong, Taiwan, Macao, Singapore, and Euro-American Chinese communities.

With the emergence of globalization, Chinese local film genre incorporating with Western culture had gradually become a trend in Chinese martial arts film since Ang Lee's film Crouching Tiger, Hidden Dragon won Oscar Best Foreign Language Film Award in 2001. Following Ang Lee, Zhang Yimou, a top Chinese local film director, directed his first foray Chinese martial arts blockbuster, Hero, and released it in 2002, hoping to open the door of oversea market of Chinese-language martial arts film. However, different from Ang Lee's great success of Crouching Tiger in Western world, Zhang's Hero did not achieve his expectation and the film was not as shining as Ang Lee's Crouching Tiger in global film market. After all, Ang Lee's Crouching Tiger gained much more praises than critics from the West, while Zhang's Hero unavoidably got some sharp critics from oversea film commentators. One of critiques was that Zhang's Hero was a kind of propaganda beautifying Chinese authoritarianism and projecting the ambitious of China's Party-State politics (Harrison, 2006). Indeed, there are different interpretations for the two influential Chinese martial arts films in the beginning of $21^{\text {st }}$ century, while, as film products, their natures of integration of globalization and localization might be more noteworthy.

Since film is a kind of cultural products, filmmakers have to consider the needs of audiences and specific cultural acceptance in both international and domestic markets. Thus, a new term "glocalization" (Robertson, 1994) is coined to describe this kind of hybrid phenomenon of integrating globalization and localization. The terminology, "glocalization", which is a mixing-word by integrating two terms i.e. "globalization" and "localization" into a single term, 
was initially developed by Robertson (1994) as a concept in sociology. More specifically, the term is originated from a Japanese jargon, i.e. "dochakuka", which is often used in Japanese business world, referring to "global localization" (Robertson, 1994: 36).

In cultural perspective, glocalization refers to "a new cultural hybrid and change of norms and practices aimed as adjusting to local mindsets" (Kraidy, 2002). Cultural hybridization elements need to be examined carefully since they play significant roles in transnational film products. According to Wang and Yeh (2005), hybridization is one of important elements in the trend of cultural globalization. It does not simply fuse two or more different cultures into a single one culture, instead the process of cultural fusion is quite complex. Specifically, this is related to add what kinds of cultural elements, while remove what other kinds of cultural elements. It is an organic process, not mechanic combine. In Wang and Yeh's (2005: 175) view, "hybridization is not merely the mixing, blending and synthesizing of different elements that ultimately forms a culturally faceless whole". It is a complex and dynamic process of cultural integration. In the process, different cultures usually tend to produce a new form together and establish new connections with each other.

In this study, two iconic Chinese Wu-Xia (martial arts) movies, i.e. Ang Lee's Crouching Tiger, Hidden Dragon (2000) and Zhang Yimou's Hero (2002), are taken as two empirical cases to make a comparative study from the perspectives of glocalization, cultural hybridization and cultural discourse analysis. More specifically, in the study, what the problems need to be concerned are what kinds of locally Chinese culture were hybridized with other modern cultural elements in the two Chinese martial arts films and how did the two films present what kinds of global-local cultural forms. Here, the main research aim is to apply an integrated perspective combined glocalization, cultural hybridization and cultural discourse to examine the two Chinese martial arts films that have been released in oversea markets in order to identify their cultural changes and adaptations through discourse representations. Significantly, in the era of globalization, Chinese transnational martial arts film, as a kind of audiovisual cultural products, has to embrace globalization, meanwhile it also has to maintain its "Chineseness", i.e. the originally oriental elements of China, which is an urgent point need to be examined carefully.

\section{LITERATURE REVIEW}

Studies of glocalization and cultural hybridization have been produced many influential papers. Pieterse (1994) proposed that globalization could be regarded as a kind of process of hybridization of different civilizations. In Pieterse's view (1994: 161), globalization is usually interpreted as that "the world is becoming more uniform and standardized, through a technological, commercial and cultural synchronization emanating from the West, and that globalization is tied up with modernity". Robertson (1994) intensively argued the concepts of globalization and localization from sociological perspective, and then further proposed that the idea of glocalization could be a refinement of globalization. Furthermore, the concept of glocalization can be introduced to the fields of sociology and communication in order to further investigate the global-local process of culture. In terms of hybrid phenomenon in cultural globalization, Kraidy (2002) theorized it and proposed "an intercontextual theory of hybridity" in which further argued cultural dynamic, hybridization and hegemony in cultural globalization. Indeed, it seems hard to avoid cultural change or hybridization in globalized process when one national culture product enters another cultural market. Chinese transnational martial arts film as a popularly cultural product is inevitably involved in the process of cultural change and hybridization.

Other researches that focus on Chinese transnational cinema have been touched upon the perspectives of globalization and localization as well as cultural hybridization (see Klein, 2004: Wang \& Yeh, 2005; Lee, 2006; Shao \& Pan, 2006; Huang, 2006; Zhu, 2013). Klein (2004) examined how the power of globalization impacts on Hollywood and East Asian film industry. She took contemporary Chinese martial arts films in America and East Asia as examples of cultural globalization to further investigate how did globalization involve in cultural homogenization and heterogeneity. In terms of specific case study, Wang and Yeh (2005) took Disney's film Mulan and Ang Lee's film Crouching Tiger, Hidden Dragon as examples to examine their globalization and hybridization strategies. In their research, three strategies or features in hybridization of cultural products had been discovered, i.e. "deculturalization", "acculturalization" and "reculturalization" (Wang \& Yeh, 2005: 177-182). Wu and Chan (2007) also took Ang Lee's Crouching Tiger, Hidden Dragon as an example to argue that Chinese martial arts film could be seen as a reversed cultural flow to against asymmetric Western hegemonically cultural flow that referred to most of cultural products or ideologies were exported from Euro-American developed counties to those developing and undeveloped countries. In their study, they comprehensively explained how the local Chinese martial arts genre film could be globalized and further pointed out that international cooperation and the balance of East-West culture in the film were key factors for the success of Ang Lee's Crouching Tiger, Hidden Dragon.

In addition, Disney's animated film Mulan seems an initial representative of hybridization of Chinese culture and the Western culture. Tian and Xiong (2013) also took Mulan as a case study to examine how Hollywood borrowed Chinese local ancient ballad as cultural resource to create a Western style film embedded Chinese theme and pointed out that cultural transfer, cultural deformation and cultural reformation were the three key elements in the film.

In the context of Chinese local film, Zhang Yimou's Hero as an initial local Chinese martial arts blockbuster that goes global market is one of research concerns in media and film studies. Zhang (2005) discussed that the world view of Hero was a kind of metaphor of resisting current world order, and proposed that Zhang Yimou's film was a representation of Chineseness and also a new form of global culture featured by Chinese gene. Zhu (2009) used Zhang Yimou's three martial arts blockbusters as cases to discuss Chinese film 
practice in globalized market and investigated cross-cultural strategies of globalized cinema. Chan and Fung (2010) comprehensively analyzed co-production films and TV products that were join-produced by Mainland China and Hong Kong by using two audiovisual products as cases, i.e. the film Hero and TV drama series The Drive of Life. They further pointed out that such kind of co-producing film and TV dramas could be seen as "structural hybridization" of cultural products. In terms of cultural politics, Zhu (2013) further focused on cultural ideological elements and intensively analyzed the metaphors related to Chinese nationalism and global order embedded in Hero's storytelling and language expressions.

Based on the literature studies, it seems that there are few researches taking a comparative angle to examine Ang Lee's Crouching Tiger, Hidden Dragon (2000) and Zhang Yimou's Hero (2002) in terms of their strategies of glocalization, global-locally cultural hybridization and cultural discursive construction. Only Chen's (2006) study made a comparative analysis to their designs of Kungfu action and $\mathrm{Wu}$-Xia (martial arts chivalry) spirits. Even though some studies had been discussed cultural hybridization and glocalization strategies, some detail elements, such as film dialogues, discourse representations and their Chinese-English translation features that reflect hybrid elements, were often neglected. This means that there is still much space to do comparative study to the two Chinese martial arts films. In this light, the study takes a comparative angle to investigate Crouching Tiger, Hidden Dragon and Hero from the dimensions of global-local cooperation, cultural hybridization and cultural discourse analysis.

\section{THEORETICAL FRAMEWORK}

The theoretical framework adopted in the study consists of glocalization concept (Robertson, 1994; Matusitz, 2011; Wu \& Chung, 2015), cultural hybridization (Pieterse, 1994; Kraidy, 2002; Wang \& Yeh 2005) and cultural discourse analysis (Shi-xu, 2005, 2008, 2014). The term, "glocalization", as aforementioned, is an integrating word that combines "global" and "local" into a single unique term that transparently shares the meanings of "globalization" and "localization". Against the backdrop of the cultural study of Chinese martial arts film, the analysis of globalization pays special attention to cross-cultural construction of the two Chinese martial arts films.

Cultural hybridization is one of representations of cultural globalization (Wang \& Yeh, 2005). Since there is exchange of goods, capitals and human resources across different regions and countries, there is cultural exchange and further facilitating cultural fusion, or hybridization. Chinese martial arts film go global essentially is Chinese culture go global. However, there is something changed in original Chinese culture when it enters diversely cultural competition in global market. This implies that in order to make specific Chinese culture be easier accepted by global audiences, especially English language audiences, Chinese martial arts film producers have to reduce cultural barriers in film stories, which is transparently showing in filmic discourses. Thus, the classical Chinese expressions, such as names of Kungfu skills, nickname of sword masters, and jargons of martial arts, used between Kungfu masters and swordsmen in film story are translated into English in a more understandable version.

Cultural approach to discourse studies is a relatively new approach to study discourse. Although discourse studies and critical discourse analysis have been experienced several decades development, it seems under-emphasized the role of culture plays in bridging discourse and society (Gavriely-Nuri, 2018). Thus, the study pays particular attention to cultural dimension of filmic discourse analysis. In addition, since the two Chinese martial arts films are strongly related to Chinese culture, it is appropriate to adopt Shi-xu's (2005, 2014) research paradigm of Chinese cultural discourse analysis. According to Shi-xu (2014), Cultural Discourse Studies (CDS) is multicultural orientation, emphasizing cultural uniqueness. It "proceeds from the basic premise that different cultural communities communicate and interact differently, in terms of worldviews, concepts, values, rules, strategies, means, channels, purposes, consequences, historical circumstances, and intra/interrelations" (Shi-xu, 2014: 361). More specifically, Chinese culture discourse studies is a model of CDS. It is "a systematic, discourse research paradigm grounded in local - Chinese - culture and open to global disciplinary dialogue" (Shi-xu, 2014: 364). In adhering to a cultural perspective, the paradigm of Chinese discourse studies is applied to examine sociocultural structures and philosophical implications that are embedded in the two classic Chinese martial arts films.

Based on the combination of glocalization, cultural hybridization and Chinese cultural discourse studies, a combined analytical framework is formed in the present study. Its overall profile is shown below, see the Figure 1.

\section{RESEARCH METHOD}

In accounting for the research methods, the study adopts qualitative textual analysis and literature research. Since the research objects are two Chinese language transnational movies, their global-local strategies are investigated by using relevant documentaries, interviews materials to the film directors and online/offline news reports. The sociocultural ideologies that are implanted in the two films are examined by interpreting film narratives and by analyzing major film characters. Furthermore, film dialogues and their English translations are collected as textual data to analyze. Importantly, it needs to settle an objective in the research, which is to get new insights from examining their processes of cultural hybridization and further to reveal their cultural identities and ideologies hidden behind filmic discourses. On the basis of the previous literature search and the theoretical framework adopted, the study concentrates on figuring out the following research questions:

i. What kinds of global and local strategies are employed by the two films?

ii. How do these two films hybridize Chinese and the Western cultures?

iii. What kinds of cultural themes the filmmakers want to express through filmic discourses and to what extent 


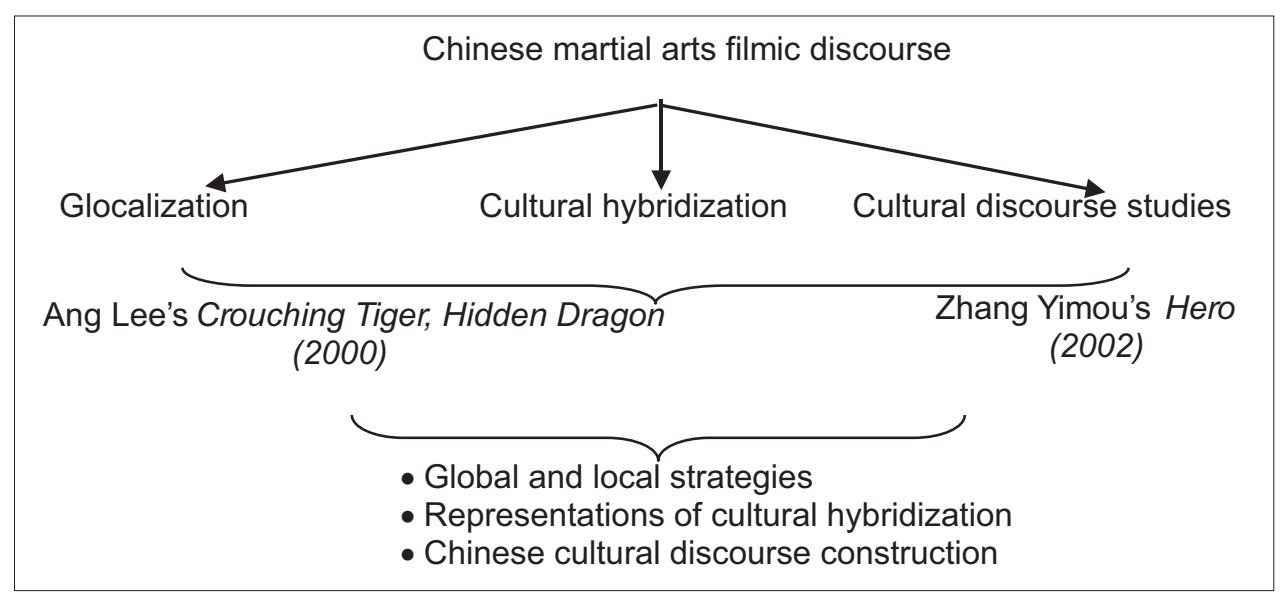

Figure 1. Overall profile of analytical framework of Chinese martial arts film discourse

they alter localized contents of Chinese martial arts film into a story that can be understood and appreciated by non-Chinese audiences, especially Western English audiences?

\section{CULTURAL ANALYSIS TO CHINESE MARTIAL ARTS FILMIC DISCOURSE IN THE CONTEXT OF GLOCALIZATION}

This section makes cultural analysis and discourse analysis to Ang Lee's Crouching Tiger, Hidden Dragon (2000) and Zhang Yimou's Hero (2002). Although the two films have almost 20 years history insofar, their influences on Chinese martial arts film cannot be ignored. What's more, the success of Chinese martial arts film in global-local markets at that time could provide a valuable insight on how Chinese traditional martial arts culture worked with the contemporary capital to create innovatively cultural products.

\section{Briefing the Film Stories}

It is necessary to sketch out a story picture for the two Chinese martial arts films before further making in-depth analysis to their global-local strategies, cultural structures of hybridization and discursive representations. The major characters' information of the two films see the Figure 2. In background, the spatial-temporal setting of the two stories are in ancient imperial China. They are featured by traditional Chinese culture and philosophies, such as Confucianism, Taoism, Legalism and China's patriarchal system. For Ang Lee's Crouching Tiger, Hidden Dragon (2000), the story is set in Qing Dynasty of China in $18^{\text {th }}$ century. It is a romantic story of martial arts about sword man, love, revenge, traditional Chinese morale conflict and reflection. The four major characters, Li Mu bai, Yu Shu Lien, Jen Yu and Lo "Dark Cloud" represent different Chinese philosophical values and Ang Lee's reflections about Chinese traditional culture.

Different from Ang Lee's film, Zhang Yimou's Hero (2002) is a grand narrative about Chinese nationalism. The story setting is in the end of the Warring States Period (475$221 \mathrm{BC}$ ) of China. It tells a story about national unity, conquering, sacrifice and Tianxia values (i.e. all-under-heaven). The story plot is driven by six characters' interactions and conflicts. They are King of Qin, Nameless, Broken Sword, Flying Snow, Long Sky and Moon. In essence, the film Hero "fabricates a discourse of Chinese history which views the birth of a nation through the choice of the first Emperor's assassins, in the hope, rightly or wrongly, of stopping the Emperor's brutal accumulation of power and territory" (Zhang, 2008: 127). The theme of Hero (2002) shows a very traditional Chinese ideology, namely, "family", "nation", "and all-under-heaven". For achieving the national unity and the dream of "all-under-heaven", individuals' interests and even life could sacrifice for the collectively national interest.

\section{Global and Local Strategies to Chinese Martial Arts Blockbusters}

Ang Lee's Crouching Tiger, Hidden Dragon (2000) and Zhang Yimou's Hero (2002) are two transnational Chinese martial arts films and they simultaneously possess globalizing and localizing features in mass media culture. The global and local strategies here can be understood as a kind of "structural hybridization" which "refers to mixed forms of organizational cooperation and increases in the range of organizational options" (Chan and Fung, 2010: 82). These features mainly manifest in three levels, namely, global capital cooperation, transnational screenplay creating and global-local teamwork.

\section{Global capital cooperation}

In Ang Lee's Crouching Tiger, Hidden Dragon, according to Klein (2004), the filmmaking involved in around five different international companies across different countries and regions. These companies include two Taiwanese companies, i.e. Edko Films (in Hong Kong) and Zoom Hunt Production (in Taiwan), two Chinese mainland companies, i.e. Asian Union Film \& Entertainment Ltd. and China Film Co-Production Corporation, and one American company, Columbia Pictures Film Production Asia. Moreover, Sony Pictures Entertainment and Columbia Pictures Film Production Asia funded largely to the film (Hu \& Chan, 2007: 205) and Sony Pictures Classics was responsible to distribute the film into global markets. After finishing the film shooting in Beijing studio and location shooting across different China provinces, the postproduction of the film, such as film editing and 


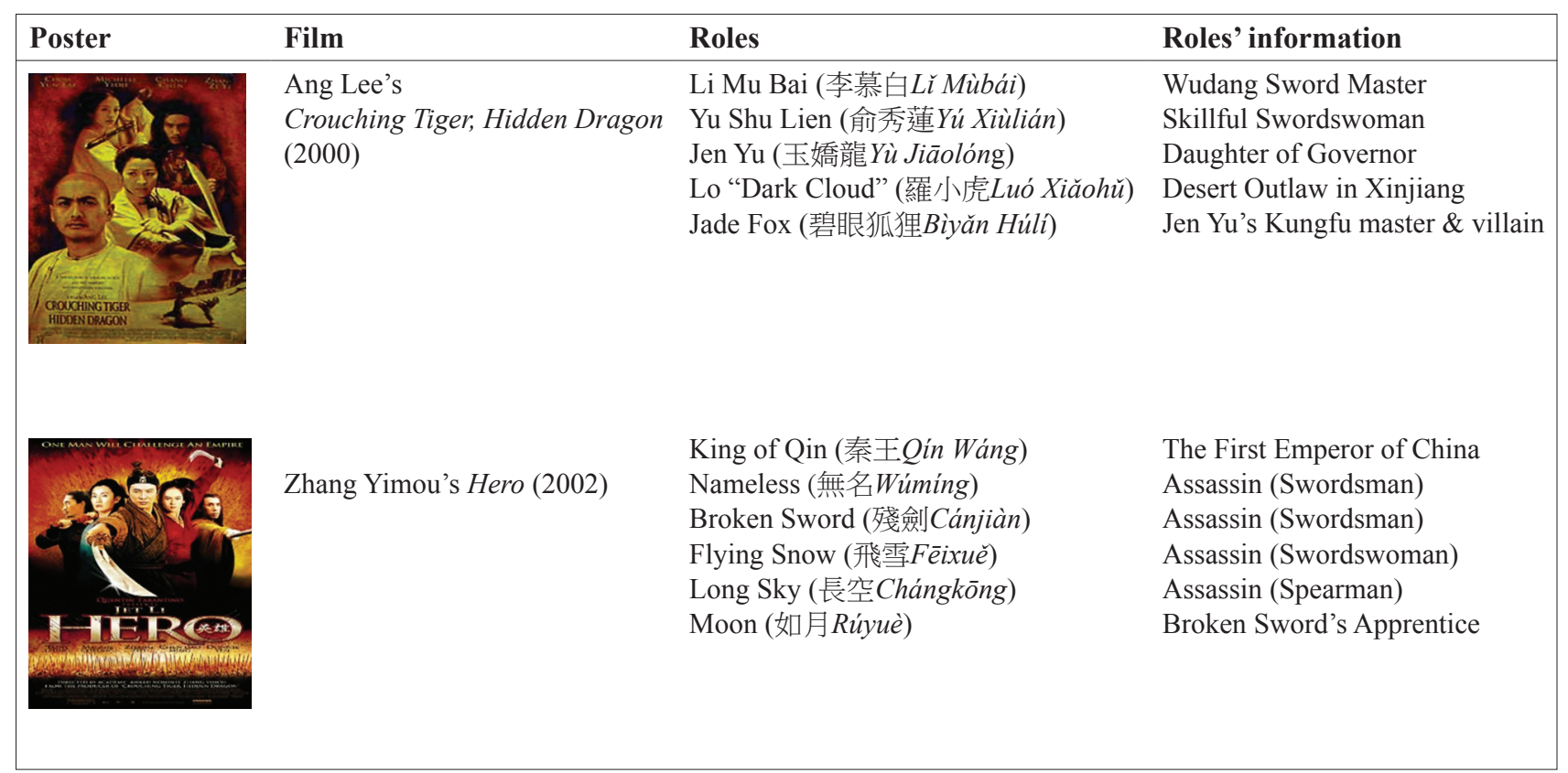

Figure 2. Characters of the two Chinese martial arts films

soundtrack recording, took place in Shanghai, Hong Kong and New York (Klein, 2004: 19).

Similar with the model of international cooperation of Crouching Tiger, Hidden Dragon, Zhang Yimou's Hero, as the first one Chinese martial arts blockbuster at that time, also adopted an international model. A Hong Kong based film company Edko Films Ltd that was ever engaged in making Ang Lee's Crouching Tiger, Hidden Dragon helped to international fundraising. Two Chinese companies, Beijing New Picture Film and China Film Group, were responsible to domestic release, meanwhile American companies, for instance, Miramax Films, Universal Pictures and Warner Brothers Entertainment distributed the film in U.K, and France and Japan, respectively (Zhu, 2009: 139). Clearly, oversea distribution and market promotion of the film were charged by multinational corporations with global market networks.

\section{Film screenplay creating}

In the part of film screenplay writing, it is no longer a lonely fighting instead it is a global screenwriting team. In Crouching Tiger, Hidden Dragon, the film script was adapted from Wang Dulu's martial arts novel initially published in 1930s and rewrote by professional screenwriters. In addition to Ang Lee, other three major screenplay co-writers include James Schamus who is Ang Lee's long-term script writing partner, Taiwan screenwriter Wang Hui-Ling and Hong Kong writer Tsai Kuo Jung (Dilley, 2015: 121). According to Schamus (2005), the process of film script writing actually is like an international cooperation.

"It was really rewriting the script so many times, translating back to English, back to Chinese, writing it and, of course, finally rewriting the film one last time in the form of the subtitles and at that moment, through discussion $[\ldots]$ realizing how little of the movie I understood. [The film's] meanings remain embedded in the Chinese language and culture."

Schamus (2005, Quoted from Dilley, 2015: 121-122)
It is thus clear that the screenwriting in Ang Lee's Crouching Tiger, Hidden Dragon is also a small-scale global cooperation process which involved in cooperation of English speaking writer and Chinese as mother language writers. There is no doubt that the film script has already been featured by global-local strategy. In this process, the classic Chinese $\mathrm{Wu}$-Xia novel has been rewritten and updated as a hybridized cultural production fused Western culture and Chinese culture both in content and discourse.

Different from Ang Lee's film, in Zhang Yimou's Hero, the writing of the film script is by Zhang Yimou, Feng Li and Bin Wang (Zhang et al., 2002). All of the screen writers are Chinese including the film director Zhang Yimou. Therefore, it is clearly noted that the screen writing process in Hero lacks of international cooperation element. The core theme of the screenplay is strongly based on Chinese culture and further highlight ancient China's military conquer and the birth of China's first united empire, i.e. the Empire of Qin. Moreover, the historical background is real, while the specific martial arts story is historically virtual. To some extent, the film, Hero, demonstrates an intertextuality of real Chinese ancient history and imaginary martial arts story.

\section{Internationalized and localized alliance}

The two Chinese martial arts films have international filmmaking team on one hand, and also Chinese local talents on the other. In Ang Lee's film, the five major film casts are Chow Yun-fat, Michelle Yeoh, Zhang Ziyi, Chang Chen and Cheng Pei-pei. Among of them, Chow Yun-fat and Cheng Pei-pei are from Hong Kong, Michelle Yeoh is Malaysian actress, Zhang Ziyi is Chinese mainland actress and Chang Chen is from Taiwan. Screenwriters as have been mentioned are from America, Taiwan and Hong Kong. The martial arts actions designed by Yuen Wo Ping who was action director of The Matrix. For the director, Ang Lee himself, he is an American Chinese director who has global vision and rich 
experience in directing Hollywood movies. He is very familiar with Hollywood film industrial standardize meanwhile he also has acute sense to Chinese traditional culture. Based on the observation, the filmmaking team is very much internationalized which across the U.S., China Mainland, Hong Kong, Taiwan and Malaysia.

In Zhang Yimou's Hero, as the first Chinese commercial blockbuster, its internationalized degree is relatively high but not as much as Ang Lee's film, instead its localized cooperation is good. For example, the major film characters are played by Jet Li, Tony Chiu-Wai Leung, Maggie Cheung, Donnie Yen, Chen Daoming and Zhang Ziyi. Just as mentioned, the film screenplay wrote by Zhang Yimou and other two Chinese local writers. The cinematographer of Hero is Christopher Doyle who is an Australian-Hong Kong people with rich experience in international filmmaking. Clearly, the participants in the filmmaking are mainly from China mainland and Hong Kong, which indicates that Hero is a Hong Kong-China co-produced movie in precisely speaking (Chan \& Fung, 2010).

In short, the global and local cooperation is helpful to strike a balance in business and culture between China and the West. It can target the needs of global market on the one hand, and also can maintain unique oriental aesthetics of Chinese martial arts film on the other. The global and local cooperation is beneficial to globalize a local film in that one is to provide financial support and the other one is to attract talents who are excel in cross-cultural filmmaking.

\section{Representations of Cultural Hybridization}

Cultural hybridization is unavoidable in transcultural film products. According to Kraidy (2017), hybridization refer to "the fusion of two hitherto relatively distinct forms, styles, or identities, cross-cultural contact, which often occurs across national borders as well as across cultural boundaries" (p. 5). The Chinese martial arts culture and Western culture definitely are two kinds of distinct forms, styles and identities based on Kraidy's (2017) concept of hybridization. Therefore, how they can be fused into a cinematic cultural form that can be accepted in global audiovisual market is a noteworthy research point. The hybridization of Chinese culture and the Western culture in Crouching Tiger, Hidden Dragon has led global audiences to struggle in its national and cultural identity (Klein, 2004: 20), while Zhang Yimou's Hero seems not so much dislocation in cultural identity understanding for both global and domestic audiences.

\section{National identity}

There is no doubt that Ang Lee's Crouching Tiger, Hidden Dragon possesses global identity that is not only in filmmaking process but also in adapting and rewriting of film story narrative. However, Ang Lee, as a Chinese-American international director, was allured by Western cultural imperialism to some extent, which sharply criticized by Elley (2001) whose view is that Crouching Tiger is a cultural bastardization and likes a well-cooked cultural chop suey appealing to general Western film audiences. In a critical angle, it is a manifestation of cultural colonization of Hollywood film industry to Chinese martial arts film genre (Klein, 2004: 20). Specifically, Ang Lee's Crouching Tiger is not merely a Chinese martial arts story crossing national boundaries, instead it is a repackaging and re-explanation of Chinese cultural identity (Dilley, 2015: 118). However, one has to admit that Ang Lee's Crouching Tiger indeed had achieved great success in global mass market as well as gained a series of film awards including Oscar Awards, British Academy Awards and Golden Globe Awards. It can be said that Crouching Tiger, Hidden Dragon is a glocalized variation of Chinese traditional Wu-Xia film against the backdrop of Western-dominant global culture. It tells a romantic story of Chinese swordsmen with Western humanism and modern narrative skills.

In contrast to Ang Lee, Zhang Yimou's Hero is more original Chinese flavor and is faithful to martial arts film style and principles. Nevertheless, its cultural politics of nationalism and totalitarianism have often been attacked by film cultural critics (Larson, 2008). Whereas, as a Chinese martial arts blockbuster that pursued Oscar, Hero's target audiences are not only Chinese but also non-Chinese audiences in which English audience is one of important target groups. However, it cannot get rid of its national and cultural politics shadow, because of Zhang Yimou's cultural identity and the environment of Chinese filmmaking that is regulated by the Party-State. Furthermore, Zhang Yimou and the same generation contemporary Chinese directors almost have been educated by the Communist Party of China (CPC) (Zhang, 2008:133) and one of the most vital doctrines is loyal to the Party, even in cinematography. China's nationalism, national unity, national identity, emperor's ambitions and assassins' self-sacrifice are core cultural-political themes in Zhang's Hero. To some extent, it had been interpreted as the theme aiming at beautifying CPC's totalitarianism and helped the Party to seek legitimacy from ancient China's ruling philosophy, i.e. Tianxia (all-under-heaven) ideology.

\section{Hybridizing culture}

As transnational films, Ang Lee's Crouching Tiger, Hidden Dragon attempts to strike a cultural balance between China and the West, while Zhang Yimou's Hero tries to input Western narrative techniques into the authentic Chinese martial arts cinema. Briefly speaking, Ang Lee's Crouching Tiger is a film hybridizing Chinese culture and the Western values under a cloak of Chinese martial arts genre. Moreover, Ang Lee's film contains multifaceted transformations. Firstly, it was transformed from a Chinese martial arts novel published in the early 1940s in China (Xu, 2006: 61). It had been experienced a textual transformation which was rewritten from a novel to a film screenplay. And then secondly, it was added Western values (e.g. feminism) to Chinese traditional culture (e.g. Confucianism and Taoism), which could be seen as a cultural hybridization. Thirdly, the narratives and scenarios of the film reflected quite rich Freudian-style metaphors, for instance, the "Green Destiny Sword" symbolizes male's phallus and ancient Chinese hierarchy power. These elements are not common in an orthodox Chinese marital arts film or novel. 
Comparatively, Zhang Yimou's Hero is a typical Chinese martial arts film reflecting Chinese nationalistic ideology under the guidelines of global and local filmmaking strategies. Zhang's Hero is relatively low cultural hybridization but high structural hybridization that refers to "mixed forms of organizational cooperation and increases in the range of organizational options" (Chan \& Fung, 2010). Moreover, in terms of color hybridization, Hero's extreme use of different colors and visual aesthetics of martial arts shows a dramatically visual style compared with clean, muted and earthy color of Crouching Tiger, Hidden Dragon (Harrison, 2006: 570). In addition, Zhang's film also targeted global market, thus, fantastic Kungfu actions and grand special effects were widely adopted so as to compensate the thinness of story content.

\section{Cultural ideology: Freedom vs. Tianxia (all-under-heaven)}

Cultural ideology plays a vital role in shaping the themes of the two Chinese martial arts films. In Ang Lee's Crouching Tiger, Taoism, Confucianism and freedom pursuit are major cultural thoughts that embody in three film characters, Li $\mathrm{Mu}$ Bai, Yu Shu Lien and Jen Yu respectively. Li Mu Bai (played by Chow Yun-fat), as a Wudang swordsman, Taoism truthiness is his ultimate pursuit while he also loves to Yu Shu Lien but he repressed his desire to Yu. Yu Shu Lien is a female warrior who was fiancée of Li's brother-hood who was killed by their enemies. Yu Shu Lien (played by Michelle Yeoh) is a representative of Confucianism that emphasizes sincerity, morality, discipline and hierarchy. Li and Yu love each other but they "honor their code of duty above their own feelings" (Dilley, 2015: 127) which led to their unspoken and repressed love and romantic tragedy ending. That's why Klein (2004: 18-19) pointed out that the theme of Crouching Tiger "is on the tension between the Characters' Taoist aspiration to follow the 'WAY' and their Confucian sense of obligation to others". In Jen Yu's role, she is a feminist symbol pursuing freedom and resisting against traditional Chinese hierarchy. She steals "Green Destiny" Sword, which triggers sequential plot events. In the following plot, Jen Yu follows her heart falling in love with an outlaw bandit leader, Lo "Dark Cloud" and has sexual intimacy with him. Thus, Yu Shu Lien and Jen Yu, the two female warriors, have been embedded Western feminism thought. To think deeply, Li Mu Bai's "Green Destiny" Sword could be seen as a symbol of phallus of patriarchal power in traditional Chinese society (Chan, 2004), which shows a Freudian illusion in a scene of martial arts fighting between $\mathrm{Yu}$ Shu Lien and Jen Yu (Dilley, 2015: 129). This reflects westernization of filmmaking and story narrative with Chinese style. Just as Ang Lee's saying: "with Crouching Tiger, for example, the subtext is very purely Chinese. But you have to use Freudian or western techniques to dissect what I think are hidden in a repressed society-the sexual tension, the prohibited feelings. Otherwise you don't get that deep." (Chan, 2004: 6)

Conversely, Zhang Yimou's Hero is full of masculinity and Chinese nationalistic spirit. Hero's story takes place in the period of Warring States prior to China's national unity.
Assassinating King of Qin is a major plot. The theme of the film is about Tianxia that can be rendered as all under the heaven or our homeland (Larson, 2010). The storytelling adopts a series of flashback happened in different assassin stages between Nameless' conversation with King of Qin whom Nameless attempts to kill at the final part (Harrison: 2006). At the last minute, Nameless does not kill King of Qin but sacrifices himself voluntarily for the King of Qin's conquering all of China, which indicates that the assassin Nameless sacrifices for Tianxia, which refers to sacrifice himself for the peace and unity of China. Just as Zhang's (2008: 131) interpretation, "Nameless gives up his vengeance for a grander political principle - the principle of unity and peace--by choosing not to kill the brutal Emperor even if he is in possession of a sword [...] The idea of peace conquers all". However, in a deeper interpretation, as Kaldis (2009: 84) saying "whether intended or not, [Zhang Yimou's Hero] is an example of commercial cinema in ideological support of the 'Chinese authoritarian state', and more broadly, of 'totalitarianism in general' (Larson 2008: 181)". Indeed, there are different readings to Hero from different cultural and ideological perspectives, but one definite point is that the authentic degree of Chinese martial arts style is higher than that of Crouching Tiger.

\section{Cultural Analysis to Filmic Discourse Construction}

Film discourses reflect cultural hybridization and deepen ideology of theme. The styles of dialogues are quite different in the two films in their original Chinese versions. In Ang Lee's Crouching Tiger, westernized film lines are very explicit, but Zhang Yimou's Hero shows very typical ancient Chinese language style, i.e. short, concise, but meaning condensed. Moreover, the two transnational films adopt Chinese mandarin, so their English subtitle translations are important when investigating their transcultural discourse communication. Let's respectively take a typical example from the two films dialogues to make discourse analysis.

Film discourses of Crouching Tiger, Hidden Dragon

- 李慕白 : 生命已經到了盡頭，我只有一息尚存。我已經 浪費了這一生,我要用這口氣對你說, 我一直深愛著你！我寧願 遊蕩在你身邊，做七天的野鬼，跟隨你。就算落進最黑暗的 地方，我的愛，也不會讓我成為永遠的孤魂。

- Li Mu Bai: My life is departing. I've only one breath left. I've already wasted my whole life. I want to tell you with my last breath, I have always loved you. I would rather be a ghost, drifting by your side as a condemned soul than enter heaven without you. Because of your love...I will never be a lonely spirit.

Film discourses of Hero

- 秦王 : 劍法, 其第一層境界 : 講求人劍合一, 劍就是人 人就是劍。手中寸草, 也是利器。其第二層境界 : 講求手中 無劍，劍在心中，雖赤手空拳，卻能以劍氣，殺敵于百步之 外。而劍法的最高境界 : 則是手中無劍心中也無劍, 是以大 胸懷包容一切，那便是不殺便是和平。

- King of Qin: What this reveals is his highest ideal. In the first stage, man and sword become one and each other. Here, even a blade of grass can be used as a lethal weapon. In the next stage, the sword resides not in the hand, but 
in the heart. Even without a weapon, the warrior can slay his enemy from 100 paces. But the ultimate ideal is... when the sword disappears altogether. The warrior embraces all around him. The desire to kill no longer exists. Only peace remains.

In Crouching Tiger's example, it is clear that the language style is very modern and looks like a romantic confession of love. For instance, "I want to tell you with my last breath, I have always loved you." This language style is rare in Chinese ancient martial arts story. Furthermore, metaphor is adopted to enhance the character's (Li Mu Bai's) love and feeling to Yu Shu Lien. Li Mu Bai rather be a "ghost" so long as he can achieve his love to Yu Shu Lien, so he says, "I would rather be a ghost, drifting by your side as a condemned soul than enter heaven without you." At the last moment of Li Mu Bai's life, he finally tells the true feeling to Yu Shu Lien, which breaks the shackle of traditional Chinese moral to pursuing his true love and deep humanity.

Differently, the example of Hero shows that the Chinese linguistic style and syntactic structure are faithful to the style of traditional Chinese martial arts genre. In accounting for their English subtitle translations, free translation method is adopted aiming to deliver as much as sense to English target audiences who have no Chinese cultural background. Hence, it shows that Couching Tiger's film discourses mainly use modern and westernized language styles, while Hero prefers to reproduce traditional Chinese language style and be faithful to the register of authentic Chinese martial arts film genre. Significantly, their English translations bridge the gap between Chinese martial arts culture and global audiences which is a manifestation of the global and local trend of Chinese transnational cinema.

Furthermore, in Ang Lee's film, the language and lines are westernized, direct, easy to understand and also easy to translate into English. The discourse of Crouching Tiger is featured by westernized expression style and logic under the cover of Chinese language and martial arts phenomenon. Through discursive representation, its inner implication is conflict and resistance between Western humanism of seeking freedom and Chinese conservative traditional ethic. The side of seeking freedom and resisting Chinese patriarchy is represented by Jen Yu and Lo "Dark Cloud", while the side of guarding traditional Chinese moral spirit is Li Mu Bai and Yu Shu Lien.

In terms of discourses in Hero, see the example, the linguistic context in original Chinese version is high context that meaning is condensed by using semi-classical Chinese syntactic structures. Its English translation although elucidated its meaning by and large, its original classic Chinese style and flavor were lost. More importantly, the King of Qin's discourse actually is the theme of Hero, which using swordsmanship as political metaphor to explain violence, killing and war in conquering other states to realize China's national unity. Essentially, the implication is beyond the discourse per se, requiring Chinese culture and historical context to interpret it. This is what Shi-xu (2009) calls "all meaning is not expressed in and through language [...] we should seek moral, imaginative, and dialogical meanings of language and life" (Shi-xu, 2009: 35) in the context of Chinese tradition.

\section{CONCLUSION}

To sum up, the study has made a comparative analysis to Ang Lee's Crouching Tiger, Hidden Dragon (2000) and Zhang Yimou's Hero (2002) from a combined perspective of integrating glocalization, cultural hybridization and cultural discourse analysis. Through analysis to the two films, the findings produced can address the three research questions proposed at the beginning. Firstly, both the two films adopted the strategies of global-local cooperation, i.e. global capital cooperation, global-local talents cooperation and global-local film script writing. Yet, the differences locate in their degrees of globalization and localization. Secondly, in terms of East-West cultural hybridization of the film contents and film discourses, Crouching Tiger repacked and fused Chinese traditional cultures, e.g. Taoism and Confucianism with Western humanism spirits, e.g. female liberation and freedom pursuit, while Hero mainly adopted Westernized filmic techniques (e.g. grand special effects, narrative skills) to tell a virtually historical martial arts tale embedded strong Chinese nationalistic identity and ideology. The purpose of employing these methods is to adapt contents of locally Chinese martial arts story to make them can be understood by global audiences. Thirdly, regarding the cultural themes of the two films, Crouching Tiger is Ang Lee's projection of imaginary cultural China which is probably never existed (Chan, 2004), while for Zhang Yimou's Hero, it can be interpreted as a recalling for China's first united ancient powerful empire and further projecting current Chinese national rejuvenation pursuing. Moreover, in discursive construction, Ann Lee preferred to adopt modern style of Chinese linguistic expressions in story narrative. Contrastively, Zhang's film attempted to restore ancient Chinese language styles to construct a historical China.

Admittedly, studies related to Ang Lee's Crouching Tiger, Hidden Dragon (2000) and Zhang Yimou's Hero (2002) have been made by relevant scholars (e.g. Klein, 2004; Chan, 2004; Larson, 2008; Zhang, 2008; Zhu, 2013). Their studies usually focus on only a single perspective, such as cultural interpretation, global and local cooperation, but sometimes neglect linguistic matters, such as differences of English translations of film dialogues and their Chinese ones and also often ignore their features of cultural hybridization in content and language. Because the language of Chinese martial arts film is mandarin Chinese, when this kind of movie genre go global, their English translation is one of urgent issues that need to be solved. Essentially, this study combined cultural studies, film studies and discourse analysis to investigate the two classic Chinese Wu-Xia films from global-local filmmaking process, strategies of cultural hybridization and their discursive styles and translations.

Moreover, the findings indicate two critical points. The first is that if Chinese martial arts movies want to successfully go global in the future, it should make a proper cultural choice between Chinese culture and Western values, sometimes maybe the Western values occupy much 
weight than the Chinese one, and create a story that global audiences especially those have no Chinese background could also appreciate, and sometimes is a reverse one. The second is that adopting a glocalization perspective combined with cultural hybridization and cultural discourse analysis to Chinese martial arts cinema can be a new path to produce novel insights in cultural, language and film studies.

However, it is unavoidable that there are several weaknesses in the research. The first one is lacking of empirical data (e.g. directly interviewing with the film directors and filmmakers) to analyze elements involved in globalization and localization of filmmaking. The second one is that the study is unavailable to provide a quantified description to show how exactly different degree of cultural hybridization existed in the two films, even though it has made detailly qualitative analysis. The last weakness is that cultural discourse analysis to the two films inevitably carries with subjective interpretations.

In short, Ang Lee's Crouching Tiger, Hidden Dragon (2000) was a stunning globalized Chinese martial arts epic with skillfully hybridizing East and West cultures and presenting deep breathtaking Chinese landscapes to global audiences. As the first martial arts epic in China mainland going global, Zhang Yimou's Hero (2002) conducted global and local strategies which made it become a successful martial arts commercial blockbuster, although it embedded Chinese cultural politics and received some sharp critics. The implication of the study shows that if Chinese martial arts films (or including other national films) want to go global successfully, they need to handle well with the global-local strategies, cultural hybridization of global-local culture as well as cultural discursive construction.

\section{REFERENCES}

Chan, K. (2004). The global return of the wu xia pian (Chinese sword-fighting movie): Ang Lee's Crouching Tiger, Hidden Dragon. Cinema Journal, 43(4), 3-17.

Chen, A. (2005). The legacy, innovation and fantasy of martial arts aesthetics: taking Crouching Tiger, Hidden Dragon and Hero as case studies. Journal of Beijing Film Academy, (4), 32-39.

Chan, J. M., \& Fung, A. Y. H. (2010). Structural hybridization in film and television production in Hong Kong. $\mathrm{Vi}$ sual Anthropology, 24(1-2), 77-89.

Dilley, W. (2015). The Cinema of Ang Lee: The Other Side of the Screen. New York: Columbia University Press. 118-133.

Elley, D. (2001). Asia to 'Tiger': Kung-Fooey. VARIETY, February 6, 2001. Available at https://variety.com/2001/ film/news/asia-to-tiger-kung-fooey-1117793240/

Gavriely-Nuri, D. (2018). Cultural approach to CDA (CCDA): From theory to practice. In Flowerdew, J., \& Richardson, J. E. (Eds.), The Routledge handbook of critical discourse studies (Routledge handbooks in applied linguistics), 171-186. Abingdon, Oxon: Routledge.

Harrison, M. (2006). Zhang Yimou's Hero and the Globalisation of Propoganda. Millennium, 34(2), 569-572.
Huang, S. (2006). Making the oriental swordsmen film - the hard way Yimou Zhang marching into the international market. Journal of School of Chinese Language \& Culture Nanjing Normal University.

Kraidy, M. M. (2002). Hybridity in cultural globalization. Communication theory, 12(3), 316-339.

Kraidy, M. (2017). Hybridity or the cultural logic of globalization. Temple University Press.

Klein, C. (2004). Martial arts and the globalization of us and Asian film industries. Comparative American Studies, 2(3), 360-384.

Kaldis, N. (2009). A Brief Response to Wendy Larson's 'Zhang Yimou's Hero: dismantling the myth of cultural power'. Journal of Chinese Cinemas, 3(1), 83-88.

Lee, V. (2006) Virtual bodies, flying objects: the digital imaginary in contemporary martial arts films, Journal of Chinese Cinemas, 1(1), 9-26

Larson, W. (2008). Zhang Yimou's Hero: dismantling the myth of cultural power. Journal of Chinese Cinemas, 2(3), 181-196.

Matusitz, J. (2011). Disney's successful adaptation in Hong Kong: A glocalization perspective. Asia Pacific Journal of Management, 28(4), 667-681.

Pieterse, J. N. (1994). Globalisation as hybridisation. International sociology, 9(2), 161-184.

Robertson, R. (1994). Globalisation or glocalisation?. Journal of international communication, 1(1), 33-52.

Shao, P. R. \& Pan, X. H. (2006). Discuss to intercultural communication strategy of Chinese film under the context of globalization. Journal of Zhejiang University (Humanities and Social Sciences), 36(01):65-73.

Shi-xu. (2005). A cultural approach to discourse. Basingstoke: Palgrave Macmillan.

Shi-xu. (2008). Towards a Cultural Turn in Discourse Analysis: Reasons, Objectives and Strategies for Constructing a Chinese Discourse Studies Paradigm. Journal of Zhejiang University (Humanities and Social Sciences), 38(1), 131-139.

Shi-xu. (2009). Reconstructing Eastern paradigms of discourse studies. Journal of Multicultural Discourses, 4(1), 29-48.

Shi-xu. (2014). In cultural dialogue with CDA: Cultural discourse studies. Critical Discourse Studies, 11(3), 360-369.

Tian, C., \& Xiong, C. (2013). A cultural analysis of Disney's Mulan with respect to translation. Continuum, 27(6), 862-874.

Wang, G., \& Yeh, E. Y. Y. (2005). Globalization and hybridization in cultural products: the cases of mulan and crouching tiger, hidden dragon. International Journal of Cultural Studies, 8(2), 175-193.

Wu, H., \& Chan, J. (2007). Globalizing Chinese martial arts cinema: The global-local alliance and the production of Crouching Tiger, Hidden Dragon. Media, Culture \& Society, 29(2), 195-217.

Wu, D. D., \& Chung, A. M. K. (2015). Glocalising Voice and Style of Cosmopolitan in China. In Ko, Chen, Ko, Leong, \& Chen, Ping (Eds.), Translation and cross-cultural communication studies in the Asia Pacific (Approaches to translation studies; v. 42). Leiden: BRILL. 
$\mathrm{Xu}, \mathrm{S}$. (2006). The leap and advancement of vitality Wang Dulu's Crouching Tiger, Hidden Dragon. Journal of Southwest China Normal University. 32(3), 61-68.

Zhang, Y. (2005). Zhang Yimou and global imaginary. Academic Monthly (1), 79-84.

Zhang, X. (2008). The death of heroes in China. China Information, 22(1), 119-137.

Zhu, Y. (2009). Global Chinese Films and Hollywood Blockbusters. The Chinese Journal of Communication and Society, (7): 133-156.
Zhu, P. (2013). "Virtuality, Nationalism, and Globalization in Zhang's Hero." CLCWeb: Comparative Literature and Culture 15.2: <https://doi.org/10.7771/1481-4374.2227>

\section{Filmography}

Lee, A., Chow, Y., Yeoh, M. et al. (2000). Crouching Tiger, Hidden Dragon. Columbia Pictures Film Production Asia et al.

Zhang, Y., Tony, C. W. L., \& Li, J. et al. (2002). Hero. Beijing New Picture Film Company et al. 